\title{
Quantification of Gear Tooth Damage by Optimal Tracking of Vibration Signatures
}

\author{
F.K. CHOY ${ }^{\mathrm{a}, *}$, R.J. VEILLETTE ${ }^{\mathrm{a}}$, V. POLYSHCHUK ${ }^{\mathrm{a}}$, M.J. BRAUN ${ }^{\mathrm{a}}$ and R.C. HENDRICKS ${ }^{\mathrm{b}}$ \\ ${ }^{\mathrm{a}}$ The University of Akron, Akron, Ohio U.S.A. 44325-3903; ${ }^{\mathrm{b}}$ NASA Lewis Research Center, Cleveland, Ohio U.S.A. 44135
}

(Received June 1996; In final form June 1996)

\begin{abstract}
This paper presents a technique for quantifying the wear or damage of gear teeth in a transmission system. The procedure developed in this study can be applied as a part of either an onboard machine health-monitoring system or a health diagnostic system used during regular maintenance. As the developed methodology is based on analysis of gearbox vibration under normal operating conditions, no shutdown or special modification of operating parameters is required during the diagnostic process.

The process of quantifying the wear or damage of gear teeth requires a set of measured vibration data and a model of the gear mesh dynamics. An optimization problem is formulated to determine the profile of a time-varying mesh stiffness parameter for which the model output approximates the measured data. The resulting stiffness profile is then related to the level of gear tooth wear or damage.

The procedure was applied to a data set generated artificially and to another obtained experimentally from a spiral bevel gear test rig. The results demonstrate the utility of the procedure as part of an overall health-monitoring system.
\end{abstract}

Keywords: Health monitoring, gears, maintenance, wigner-ville distribution, time-frequency analysis, Optimal tracking

\section{INTRODUCTION}

In the last two decades, with demands for higher operating speeds and greater load capacity, premature failures in high-performance turbomachinery have often resulted in enormous financial losses and, at times, catastrophic consequences. In aeronautical applications, where both weight and efficiency are pushed to their design limits, the prevention and management of premature equipment failures is a vital part of the maintenance program. Current onboard condition-monitoring systems for gas turbine engines often fail to provide sufficient time between warning and failure for safety procedures to be implemented. On the other hand, inaccurate interpretation of operating conditions may result in false alarms and unnecessary repairs and downtime. The early detection of incipient failure in a mechanical system is of great practical importance as it permits scheduled inspec-

*Corresponding author. Tel.: 330-972-6847. Fax: 330-972-6037. E-mail: fchoy@uakron.edu. 
tions without costly shutdowns and indicates the urgency and locations for repair before a system incurs catastrophic failure.

Some success has been achieved in identifying damage in a gear transmission system by using a joint time-frequency analysis known as the Wigner-Ville distribution (WVD) technique Boashash and Black [1987], Choy et al. [1994], Claasen and Mecklenbrauker [1980]. The approach is to use statistical pattern recognition to match the WVD signature patterns of damaged gears with standard patterns stored in a data base. Although the WVD technique is useful for determining the type and location of the damage, it is not much help in quantifying the level of damage. Damage quantification would logically be the next step in failure prediction; however, no explicit attempts at damage quantification have previously appeared in the literature.

This paper presents a new technique for processing vibration data to quantify the level of damage in a gear transmission system. The technique consists of a nonlinear numerical optimization in the form of an "optimal tracking" problem (Sage [1968], Lewis [1986]). The optimization uses a dynamic model of the gear mesh and forms an estimate of the timevarying mesh stiffness that best corresponds to the given set of vibration data. The utility of the technique relies on the relationship between the wear or damage of a gear tooth and the change in stiffness of the mesh during a given tooth pass cycle. An analysis of this relationship demonstrates that the perturbation of the stiffness function from the nominal profile can be used to quantify the level of damage.

The optimal tracking technique for estimating the perturbation of the mesh stiffness was tested in two settings. First, it was tested on a set of fictitious data generated by computer simulation of a one-degreeof-freedom mechanical system with time-varying stiffness. The solution of the optimal tracking problem matched very closely the actual stiffness profile used in the model generating the data. Then, the technique was tested on a set of experimental data from a gear test rig, but still assuming the one-degree-offreedom model. Despite the simplicity of the model the stiffness profile obtained was shown to be useful in correlating to the level of damage of the gear transmission system.

The paper is organized as follows: Section 2 presents the system model and formulates the optimal tracking problem. Section 3 outlines the numerical solution procedure for the nonlinear optimization. Section 4 presents and interprets the results of the optimization and discusses the next steps to be taken in developing a comprehensive failure-prediction procedure.

\section{OPTIMAL TRACKING PROBLEM}

\subsection{System Model}

The system considered in this study consisted of a small pinion in mesh with a larger gear. A simple model of this system has the two gear masses connected by a spring and a damper. The larger gear is much heavier than the pinion; hence, it is assumed to be rigid, so that all relative motion between the two is attributed to the motion of the pinion. Then, the equation of motion of the pinion takes the form

$$
m \ddot{x}+c \dot{x}+k(t) x=0
$$

where $m$ is the mass of the pinion and $k(t)$ and $c$ are the stiffness and damping of the mesh. The mesh stiffness is not constant but is nominally a periodic function of the gear angle, with each period corresponding to one tooth pass. The high points on the periodic stiffness function correspond to gear angles where two pairs of gear teeth are in contact, and the low points correspond to angles where only one pair is in contact.

It has been found in experiments on gearbox vibrations (Choy et al. [1994], [1995]) that the gear mesh stiffness changes with the wear, pitting, or fracture of the gear teeth. Such changes in the gear mesh stiffness inevitably lead to changes in the vibration signatures of the mechanical system. The objective of the optimal tracking procedure developed in this study is to reconstruct the true stiffness profile for a 
damaged gear tooth from the measured vibration. That is, the objective is to determine the function $k(t)$ that would result in the measured vibration according to the system model (1).

The true stiffness profile can be expressed as the sum of a constant (time averaged) component, a nominal periodic component, and a perturbation resulting from gear wear or damage. Accordingly, the system model (1) is written as

$$
m \ddot{x}+c \dot{x}+\left[k_{\text {ave }}-k_{\text {periodic }}-k_{\text {peturb }}(t)\right] x=0,
$$

or

$$
\ddot{x}+\frac{c}{m} \dot{x}+\Omega^{2} x=u(t) x,
$$

where $\Omega^{2}=k_{a v e} / m$ and $u(t)$ represents the total timevarying component of the stiffness divided by the pinion mass. By defining the variables

$$
x_{1}=\dot{x}, \quad x_{2}=x
$$

the system model can be written in the state-variable form

$$
\begin{aligned}
& \dot{x}_{1}=-\frac{c}{m} x_{1}-\Omega^{2} x_{2}+u(t) x_{2} \\
& \dot{x}_{2}=x_{1}
\end{aligned}
$$

with the given initial conditions

$$
x_{1}\left(t_{0}\right)=\dot{x}_{0}, \quad x_{2}\left(t_{0}\right)=x_{0} .
$$

\subsection{Optimization Problem}

Suppose that a data set corresponding to the vibration of the pinion is collected over the interval $\left[t_{0}, t_{f}\right]$. Let the function describing the data set be denoted as $\tilde{x}_{2}(t)$, since it corresponds to the modeled variable $x_{2}$ $(t)$. The objective is to determine a reasonable timevarying stiffness component $u(t)$ for which the model output $x_{2}(t)$ approximates the measured data $\tilde{x}_{2}(t)$.

A diagram depicting the functional objective is shown in Fig. 1. In the figure $u(t)$ is depicted as an input to be chosen so that the error $e(t)$ will be small for all time. Note that this problem has the form of a tracking problem, where the control input of a system is designed so that the system output follows a prescribed reference function. Such a problem may be approached by using the standard techniques of optimal control theory (Sage [1968], Lewis [1986]). In particular, the "design" of a suitable function $u(t)$ may be achieved by minimizing the quadratic cost functional

$$
\begin{gathered}
J=\frac{1}{2} \beta_{f}\left(x_{2}\left(t_{f}\right)-\tilde{x}_{2}\left(t_{f}\right)\right)^{2}+\frac{1}{2} \int_{t_{o}}^{t_{f}}\left\{\beta_{1}\left(x_{2}(t)-\tilde{x}_{2}(t)\right)^{2}\right. \\
\left.+\beta_{2} u^{2}(t)\right\} d t
\end{gathered}
$$

where $\beta_{1}, \beta_{2}$, and $\beta_{f}$ are cost-function weighting coefficients. This form of the cost functional penalizes the energy in the error between the modeled output and the measured data. It also penalizes the use of too large a stiffness perturbation function in order to avoid singularity in the solution.

In the optimal tracking problem the system dynamic equations (5) are treated as equality constraints imposed in the optimization of the cost (7). As such, they are appended to the cost function by using timevarying Lagrange multipliers $\lambda_{1}(t)$ and $\lambda_{2}(t)$. These Lagrange multipliers are themselves governed by dif-

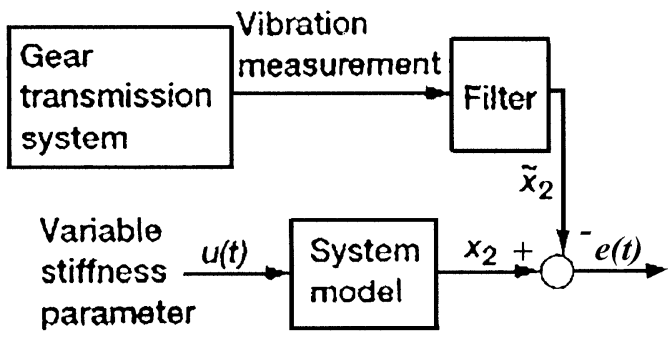

FIGURE 1 Block diagram of tracking problem 
ferential equations called the costate equations. The costate equations together with the state equations of the system model form a two-point boundary value problem (TPBVP) (Sage [1968], Lewis [1986]). The TPBVP equations are

(State equations)

$$
\begin{aligned}
& \dot{x}_{1}=-\frac{c}{m} x_{1}-\Omega^{2} x_{2}+u(t) x_{2} \\
& \dot{x}_{2}=x_{1}
\end{aligned}
$$

(Costate equations)

$$
\begin{aligned}
& \dot{\lambda_{1}}=-\lambda_{2}+\frac{c}{m} \lambda_{1} \\
& \dot{\lambda_{2}}=\Omega^{2} \lambda_{1}-u(t) \lambda_{1}-\beta_{1}\left(x_{2}(t)-\tilde{x}_{2}(t)\right)
\end{aligned}
$$

(Stationarity condition)

$$
0=\lambda_{1} x_{2}+\beta_{2} u(t)
$$

(Endpoint conditions)

$$
\begin{aligned}
& x_{1}\left(t_{0}\right)=\dot{x}_{0}, x_{2}\left(t_{0}\right)=x_{0} \\
& \lambda_{1}\left(t_{f}\right)=0, \lambda_{2}\left(t_{f}\right)=\beta_{f}\left(x_{2}\left(t_{f}\right)-\tilde{x}_{2}\left(t_{f}\right)\right) .
\end{aligned}
$$

The TPBVP (8-12) represents a set of necessary conditions for $u(t)$ to be the solution of the optimal tracking problem. The TPBVP consists of a set of four coupled differential equations (8-9), together with an algebraic relation (10), and some endpoint conditions (11-12) at both $t_{0}$ and $t_{f}$. Notice that the TPBVP is nonlinear: the unknown function $u(t)$ multiplies other independent variables in the differential equations.

\section{NUMERICAL SOLUTION PROCEDURE}

The nonlinear TPBVP (8-12) is solved by an iterative procedure. A complete and general derivation of the procedure is given in Sage [1968] and Dyer and McReynolds [1970]. Some of the salient points are outlined below for convenience.

\subsection{Successive Sweep Method}

Solving the nonlinear TPBVP requires an iterative method. Although several approaches are possible, a common and useful one is to begin with an initial guess $u^{0}(t)$ and use it to integrate the nonlinear state equations (8) forward in time starting from the initial conditions (11) to determine the nominal state functions $x_{1}^{0}(t)$ and $x_{2}^{0}(t)$. Then, starting from the final conditions (12), integrate the nonlinear costate equations backward in time to determine the nominal costate functions $\lambda_{1}^{0}(t)$ and $\lambda_{2}^{0}(t)$. The nominal functions $u^{0}(t)$, $x_{1}^{0}(t), x_{2}^{0}(t), \lambda_{1}^{0}(t)$, and $\lambda_{2}^{0}(t)$ then satisfy all the TPBVP equations except the stationarity condition (10).

The nominal state, costate, and input functions must be iteratively updated, so that they will eventually satisfy all the nonlinear TPBVP equations, including the stationarity condition. Each update is accomplished by solving a linearized version of the TPBVP. A standard method for doing this is known as the sweep method, whereby a linear relationship between the state and costate functions is assumed. Then, the linear TPBVP degenerates into a set of ordinary differential equations with endpoint conditions at the final time only. These are solved by a straightforward numerical integration. In the case of the optimal tracker these ordinary differential equations take the form of the coupled Riccati equations

$$
\begin{gathered}
\dot{p}_{11}=2\left(\frac{c}{m} p_{11}-p_{12}\right)+p_{11}^{2} \frac{x_{2}^{2}}{\beta_{2}} \\
\dot{p}_{12}=\frac{c}{m} p_{12}-p_{22}-p_{11}\left(-\Omega^{2}+u(t)-\frac{1}{\beta_{2}} \lambda_{1} x_{2}\right) \\
+p_{11} p_{12} \frac{x_{2}^{2}}{\beta_{2}}
\end{gathered}
$$

$$
\begin{gathered}
\dot{p}_{22}=-2 p_{12}\left(-\Omega^{2}+u(t)-\frac{1}{\beta_{2}} \lambda_{1} x_{2}\right)+p_{12}^{2} \frac{x_{2}^{2}}{\beta_{2}} \\
-\left(\beta_{1}+\frac{\lambda_{1}^{2}}{\beta_{2}}\right)
\end{gathered}
$$


with endpoint conditions

$$
p_{11}\left(t_{f}\right)=p_{12}\left(t_{f}\right)=0, \quad p_{22}\left(t_{f}\right)=\beta_{f}
$$

together with the auxiliary linear equations

$$
\begin{gathered}
\dot{h}_{1}=h_{1}\left(\frac{c}{m}+p_{11} \frac{x_{2}^{2}}{\beta_{2}}\right)-h_{2}-p_{11} \varepsilon \frac{x_{2}}{\beta_{2}}\left(\lambda_{1} x_{2}+\beta_{2} u(t)\right) \\
\dot{h}_{2}=-h_{1}\left(-\Omega^{2}+u(t)-\frac{1}{\beta_{2}} \lambda_{1} x_{2}-p_{12} \frac{x_{2}^{2}}{\beta_{2}}\right) \\
-\frac{\varepsilon}{\beta_{2}}\left(\lambda_{1} x_{2}+\beta_{2} u(t)\right)\left(p_{12} x_{2}+\lambda_{1}\right)
\end{gathered}
$$

with the endpoint conditions

$$
h_{1}\left(t_{f}\right)=h_{2}\left(t_{f}\right)=0 \text {. }
$$

Note that the $x$ and $\lambda$ variables in the differential equations (13) and (15) represent the given nominal functions. (The zero superscripts have been omitted for convenience.) They are simply treated as timevarying coefficients in the numerical integration of the differential equations. The solutions of equations (13) and (15) are then used to compute the corrections to the nominal state, costate, and input functions. This computation requires yet another numerical integration, this time of the linearized state equations

$$
\begin{aligned}
\Delta \dot{x}_{1}= & -\Delta x_{1}\left(\frac{c}{m}+p_{11} \frac{x_{2}^{2}}{\beta_{2}}\right)+\Delta x_{2}\left(-\Omega^{2}+u(t)\right. \\
& \left.-\frac{1}{\beta_{2}} \lambda_{1} x_{2}-p_{12} \frac{x_{2}^{2}}{\beta_{2}}\right) \\
& -h_{1} \frac{x_{2}^{2}}{\beta_{2}}+\varepsilon \frac{x_{2}}{\beta_{2}}\left(\lambda_{1} x_{2}+\beta_{2} u(t)\right) \\
\Delta \dot{x}_{2}= & \Delta x_{1}
\end{aligned}
$$

with the zero initial conditions

$$
\Delta \mathrm{x}_{1}\left(\mathrm{t}_{0}\right)=\Delta \mathrm{x}_{2}\left(\mathrm{t}_{0}\right)=0 .
$$

Finally, the update of the nominal control is computed as

$$
\begin{aligned}
\Delta u=\frac{\varepsilon}{\beta_{2}}\left(\lambda_{1} x_{2}+\right. & \left.\beta_{2} u(t)\right)-\frac{1}{\beta_{2}}\left(\lambda_{1} \Delta x_{2}+x_{2}\left(p_{11} \Delta x_{1}\right.\right. \\
& \left.\left.+p_{12} \Delta x_{2}+h_{1}\right)\right)
\end{aligned}
$$

where $\varepsilon$ is the step size, and the new nominal control is given by

$$
u^{i+1}(t)=u^{i}(t)+\Delta u^{i}(t)
$$

(The superscripts $i$ and $i+1$ denoting the iteration number have been reinserted in equation (20).) The procedure is repeated until the nominal functions converge to a solution.

The real scalar $\varepsilon \in[0,1]$ in equations (15), (17), and (19) is used as a "step size" parameter. Using a smaller value of $\varepsilon$ tends to decrease the magnitudes of the corrections, thereby improving the stability of the iterative procedure but slowing the convergence to the solution. Using a larger value of $\varepsilon$ has the opposite effects.

\subsection{Numerical Details}

The choices of the cost-function weighting coefficients $\beta_{1}, \beta_{2}$, and $\beta_{f}$ are important for effective numerical optimization. The parameter $\beta_{1}$ defines the penalty on the difference between the calculated and reference vibration signals. Since the goal is to minimize the difference between the calculated and tracked vibration signals, a large weighting coefficient $\beta_{1}$ should be chosen. The parameter $\beta_{2}$ defines the penalty on the function $u(t)$. Generically speaking, $\beta_{2}$ should impose a lighter penalty on $u(t)$ than $\beta_{1}$ imposes on the tracking error. Note also that the choice of units has an effect on the appropriate relative sizes of $\beta_{1}$ and $\beta_{2}$. In the examples studied the numerical values of $u(t)$ are considerably larger in 
magnitude than those of a reasonable vibration-signal error; therefore, even if equal weighting between error and control were desired, $\beta_{2}$ should be chosen to be considerably smaller than $\beta_{1}$. An inappropriately large choice of the parameter $\beta_{2}$ would make the cost function almost unchanged from one iteration to the next. Thus, a small constant value was chosen for the parameter $\beta_{2}$. The parameter $\beta_{f}$ defines the penalty for the error at the final time. If $\beta_{f}$ is too small, a large vibration error at the final time will result.

By following these general guidelines the optimization algorithm described in the previous section was realized in a computer program. The equations were integrated with a seventh-order Runge-KuttaFehlberg method. A summary of the programming steps is given below:

0 . Set $i=0$ and take the initial guess $u^{0}(t)$ for the function $u(t)$ to be zero.

1. Using the function $u^{i}(t)$ from the previous step, integrate the state equations (8) forward in time. Calculate the resulting cost function $J^{i}$.

2. Integrate the costate equations (9) backward in time.

3. Use the computed state and costate variables as time-varying coefficients in the integration of the Riccati equations (13) along with the auxiliary equations (15) backward in time.

4. Integrate the linearized state equations (17) forward in time. Using the linearized stationarity condition (19), calculate the correction $\Delta u^{i}(t)$ to the nominal function $u^{i}(t)$ and hence the updated function $u^{i+1}(t)$. Also, calculate the new cost function $J^{i+1}$.

5. Make decisions about the continuation of the optimization procedure and the choice of the parameters:

a. If the difference between the calculated and tracked vibration signals is small, the optimization procedure is finished.

b. If the difference $J^{i+1}-J^{i}<0$ is large enough, repeat from step 1 .

c. If the difference $J^{i+1}-J^{i}<0$ is too small, increase the weighting $\beta_{1}$ and repeat from step 1. d. If $J^{i+1}>J^{i}$, repeat from step 1 using a smaller value of the step size $\varepsilon$. If this is not successful, increase the error weighting $\beta_{1}$ and repeat from step 1.

Some comments should be made on step 5 of the numerical procedure. It was observed that for given values of weighting coefficients and the step-size parameter the optimization procedure converges to some value of the cost function. In this case the difference between the values of the cost functions $J^{i+1}$ - $J^{i}$ becomes negligible after some iterations. This means that the cost associated with the control $u(t)$ is becoming dominant. Therefore, it makes sense to start a new iteration with an increased weight $\beta_{1}$ (i.e., imposing a higher penalty on the vibration error).

\section{DISCUSSION OF RESULTS}

To demonstrate the optimal tracking procedure described above, two numerical cases were used in this study. The first case was a numerical experiment in which the tracker was applied to a set of vibration signals generated numerically, assuming a given gear mesh stiffness profile. The mesh stiffness profile evaluated by the optimal tracker was compared with the original stiffness used in generating the vibration signal. Figure 2(a) shows the comparison between the vibration signal generated by a sinusoidal stiffness and that simulated by the optimal tracker. As shown in the figure the two vibration signals were very similar; the small difference between the two signals is given in Fig. 2(b). Figure 3(a) depicts the original gear mesh stiffness used and the stiffness evaluated by using the optimal tracker; the difference between the two stiffnesses is given in Fig. 3(b). The excellent agreement between the two stiffnesses in this numerical experiment has confirmed the applicability of the optimal tracking procedure in evaluating system stiffness changes from system vibration signals. However, this close resemblance between the generated and simulated signals was partly due to the original time signals being smooth, continuous, and harmonic without any substantial change in magnitude and 


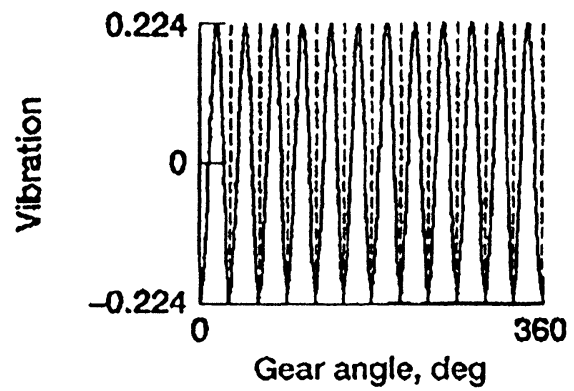

(a)

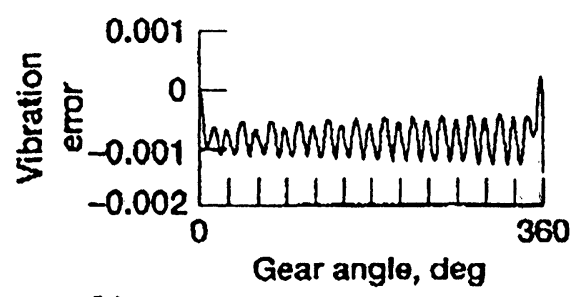

(b)

FIGURE 2 Original and tracker-simulated vibration signals for numerical experiment and error between them. (a) Signals. (b) Error.

phase over the gear revolution. To demonstrate the generality and limitation of the developed procedure, a set of experimental data taken from a test rig was used in the next case.

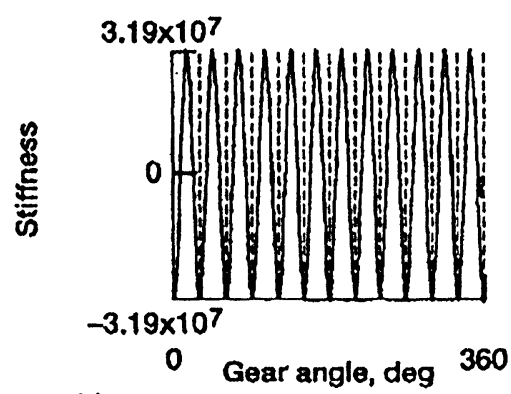

(a)

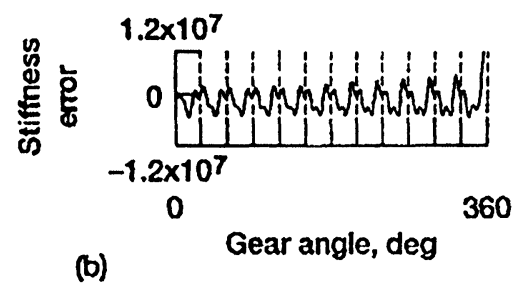

FIGURE 3 Original and tracker-evaluated mesh stiffness for numerical experiment and error between them. (a) Stiffnesses. (b) Error.
The second case was based on the experimental data obtained from the spiral bevel gear test rig shown in Fig. 4. The primary purpose of this rig is to study the effects of gear tooth design, gear materials, and lubrication types on the fatigue strength of aircraft-quality gears (Zakrajsek et al. [1994]). Because spiral bevel gears are used extensively in helicopter transmissions to transfer power between nonparallel intersecting shafts, using this fatigue rig for diagnostic studies is extremely practical. Vibration data from an accelerometer mounted on the pinion shaft bearing housing were captured by using a personal computer with an analog-to-digital conversion board and an anti-aliasing filter. The 12-tooth test pinion and the 36tooth gear have the following characteristics: 0.5141 in pitch, $35^{\circ}$ spiral angle, 1 -in. face width, $90^{\circ}$ shaft angle, and $22.5^{\circ}$ pressure angle. The pinion transmits $720 \mathrm{hp}$ at a nominal speed of $14400 \mathrm{rpm}$. The test rig was started and stopped several times for gear damage inspection. The test was ended at 17.72 operational hours when a broken portion of a tooth was found visually during one of the shutdowns.

Figure 5(a) depicts the gear tooth after $6.5 \mathrm{hr}$ of operation. Note that there is heavy surface pitting on one gear tooth with minor pitting on the next tooth. Figure 5(b) shows the time domain averaging, the frequency spectrum, and the joint time-frequency analysis using the Wigner-Ville distribution (WVD) (Boashash and Black [1987], Choy et al. [1994], [1995], Claasen and Mechlenbrauker [1980]) of the accelerometer signal at $6.5 \mathrm{hr}$ (Choy et al. [1994]). Note that in Fig. 5(b) the time signal indicates a large vibratory signal during the engagement of the sixth

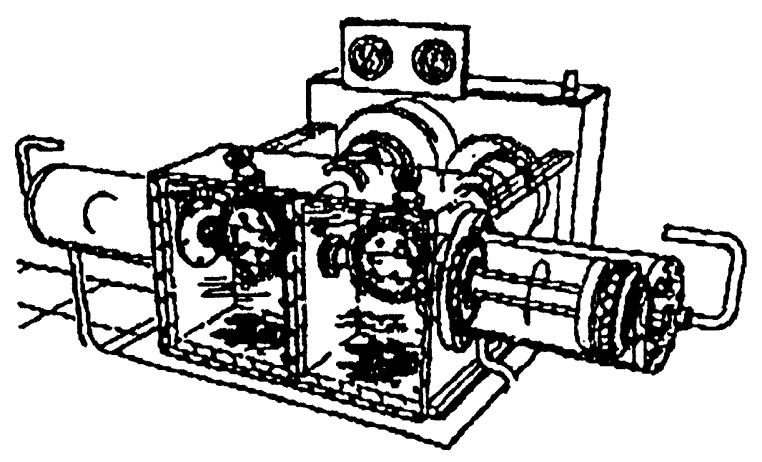

FIGURE 4 Experimental spiral bevel gear test rig. 


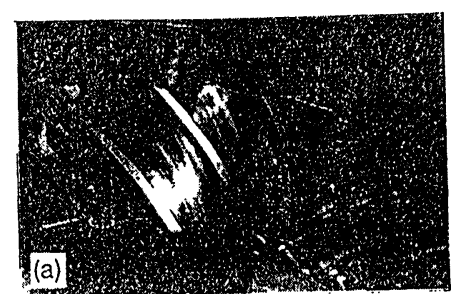

360
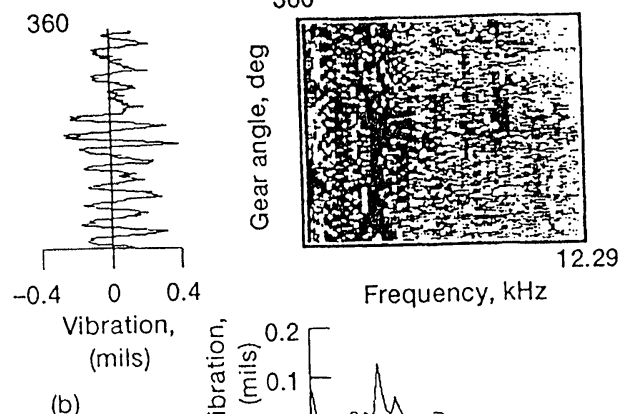

Frequency, $\mathrm{kHz}$

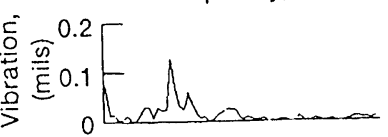

FIGURE 5 (a) Damaged gear tooth at $6.5 \mathrm{hr}$. (b) Time signal, WVD, and frequency spectrum of vibration signal at $6.5 \mathrm{hr}$.

and seventh teeth (damaged teeth), but the frequency spectrum, because of its averaging characteristics, shows very little change from the original signal (Choy et al. [1994]). The WVD begins to show a pattern of shifting of the major frequency component (at a mesh frequency of $2880 \mathrm{~Hz}$ ) around the meshing of the sixth and seventh teeth. The WVD pattern in this case is very similar to those resulting from a short-term amplitude and phase change of a vibration signal (Choy et al. [1994]). Although it has been established by the authors in some previous publications (Choy et al. [1994], [1995]) that such damage in the gear can be identified by the WVD pattern recognition process, the level of the damage has not been addressed. A recent study by the authors has shown that wear and surface pitting of the gear tooth usually will result in a phase shift in the stiffness profile, without any significant change in the stiffness magnitude. Figure 6 shows the stiffness change in a gear mesh evaluated (Boyd and Pike [1985]) from gear tooth surface profile variations. Note in Fig. 6(b) that increasing surface profile variation increases the phase shift of the gear stiffness without changing the magnitude of the stiffness.
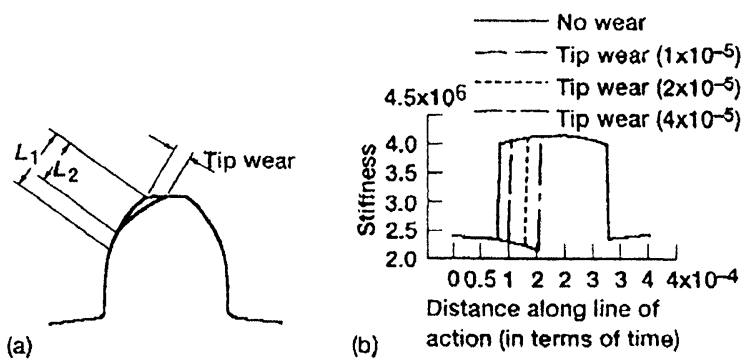

FIGURE 6 Simulated gear tooth wear and corresponding gear stiffness. (a) Simulated gear tooth wear. $L_{2}:: L_{1}=$ percent of engagement profile wear. (b) Gear stiffness from calculated simulated tooth wear.

Incorporating this constant gear mesh stiffness as an additional constraint, the optimal tracking procedure was applied to the experimental vibration signal (obtained from the bevel gear test rig at $6.5 \mathrm{hr}$ as shown in Fig. 5) to evaluate the corresponding gear mesh stiffness. To better evaluate the gear mesh stiffness, the time signal was filtered at a mesh frequency of $2880 \mathrm{~Hz}$. Figure 7(a) shows the comparison between the unfiltered experimental signal and the optimal tracker simulation, and Fig. 7(b) shows the com-
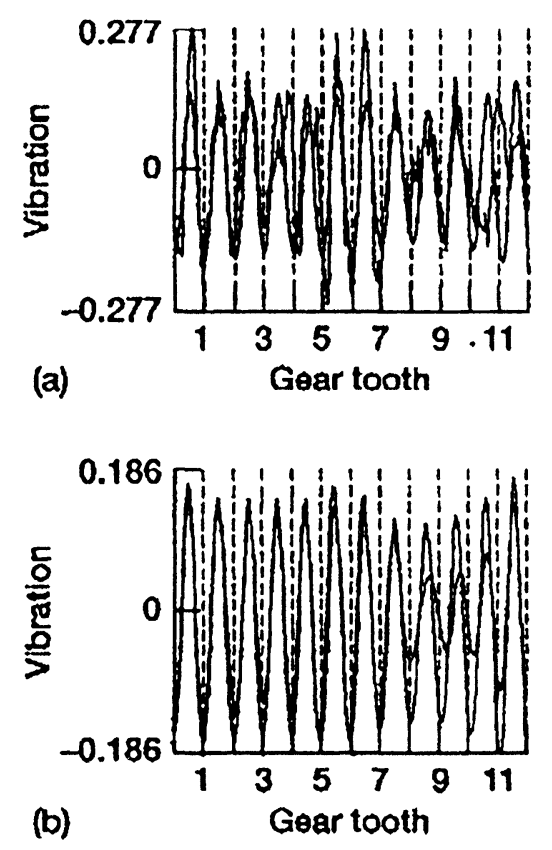

FIGURE 7 Filtered and unfiltered experimental and tracker-simulated vibration signals for spiral bevel gear at $6.5 \mathrm{hr}$. (a) Unfiltered. (b) Filtered. 


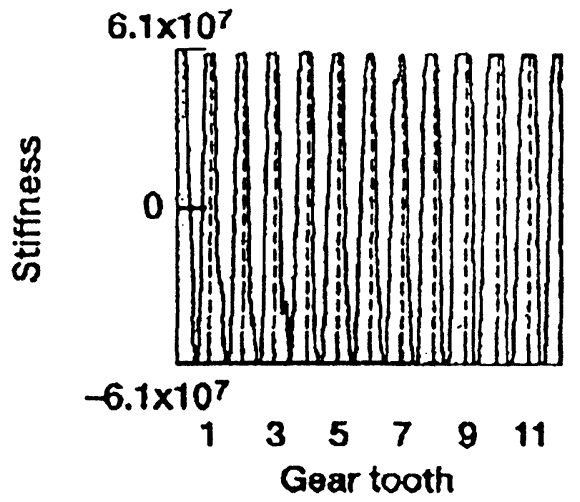

FIGURE 8 Tracker-evaluted mesh stiffness for spiral bevel gear at $6.5 \mathrm{hr}$.

parison between the filtered experimental signal and the tracker-simulated signal. Note that because of the substantial change of magnitude and phase of the time signal during the data acquisition period (one revolution of the gear), the accuracy in the simulated vibration is not as good as that in the numerical experiment (Fig. 2(a)). Figure 8 depicts the gear mesh stiffness evaluated by using the optimal tracker. Note that in the evaluated stiffness considerable phase shifts at several gear teeth resulted in the large variation in magnitude and phase of the vibration signal. At the location where pitting occurred (teeth 6 and 7) the phase shift of the stiffness was more pronounced. By using the results from the evaluated mesh stiffness and the correlation of stiffness change with gear wear shown in Fig. 6(b), the gear damage can be estimated.

\section{CONCLUSIONS}

This paper presents a unified approach to identifying and quantifying damage in a gear transmission system. The conclusions from this study are as follows:

1. The application of the joint time-frequency technique called the Wigner-Ville distribution provides the ability to identify the types and locations of the gear damage.
2. The optimal tracker developed in this paper provides a very reasonable estimate of the stiffness change due to damage, which can be related to the level of gear damage.

3. For vibratory signals with large changes in magnitude and phase angle the accuracy of the simulated signal from the optimal tracker may decrease.

4. For a more accurate evaluation of system mesh stiffness an optimal tracker for the complete dynamic model of the system is needed.

\section{References}

[1] Boashash, B. and Black, P.J., 1987, An Efficient Real-Time Implementation of the WignerVille Distribution, IEEE Trans. on Acoustics, Speech, and Signal Processing, Vol. ASSP-35, No. 11

[2] Boyd, L.S. and Pike, J., 1985, Multi-Mesh Gear Dynamics Program Evaluation and Enhancements, NASA Contractor Report 174747, Prepared for Lewis Research Center under Contract NAS3-23928.

[3] Choy, F.K., Huang, S., Zakrajsek, J.J., Handschuh, R.F. and Townsend, D.P., 1994, Vibration Signature Analysis of Faulted Gear Transmission System, 30th AIAA Joint Propulsion Conference, paper 94-2937, Indianapolis, IN.

[4] Choy, F.K., Braun, M.J., Polyshchuk, V., Zakrajsek, J.J., Handschuh, R.F. and Townsend, D.P., 1994, Analytical and Experimental Vibration Analysis of a Faulty Gear System, AGMA Fall Technical Meeting, St. Louis, MO.

[5] Choy, F.K., Polyshchuk, V., Zakrajsek, J.J., Handschuh, R.F. and Townsend, D.P., 1995, Analysis of the Effects of Surface Pitting and Wear on the Vibrations of a Gear Transmission System, Tribology International, Vol.29, No.1, pp.7783.

[6] Claasen, T.A.C.M. and Mecklenbrauker, W.F.G., The Wigner Distribution-A Tool for Time-Frequency Signal Analysis, 1980, Part I, Philips J. Res., Vol. 35, No.3, pp. 217-250.

[7] Dyer, P. and McReynolds, S.R., 1970, The Computation and Theory of Optimal Control, Academic Press.

[8] Lewis, F.L., 1986, Optimal Control, Wiley.

[9] Sage, A.P., 1968, Optimal Systems Control, Prentice-Hall.

[10] Zakrajsek, J.J., Handschuh, R.F. and Decker, H.J., 1994, Application of Fault Detection Techniques to Spiral Bevel Gear Fatigue Data, Proc. 48th Mechanical Failures Prevention Group Meeting, Office of Naval Research, Wakefield, MA; also NASA TM-106467. 


\section{ait \\ ENERGY MATERIALS}

M A N E Y publishing

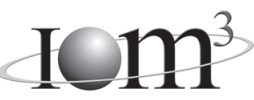

\section{Materials Science \& Engineering for Energy Systems}

Maney Publishing on behalf of the Institute of Materials, Minerals and Mining

The Institute of Materials, Minerals \& Mining

Economic and environmental factors are creating ever greater pressures for the efficient generation, transmission and use of energy. Materials developments are crucial to progress in all these areas: to innovation in design; to extending lifetime and maintenance intervals; and to successful operation in more demanding environments. Drawing together the broad community with interests in these areas, Energy Materials addresses materials needs in future energy generation, transmission, utilisation, conservation and storage. The journal covers thermal generation and gas turbines; renewable power (wind, wave, tidal, hydro, solar and geothermal); fuel cells (low and high temperature); materials issues relevant to biomass and biotechnology; nuclear power generation (fission and fusion); hydrogen generation and storage in the context of the 'hydrogen economy'; and the transmission and storage of the energy produced.

As well as publishing high-quality peer-reviewed research, Energy Materials promotes discussion of issues common to all sectors, through commissioned reviews and commentaries. The journal includes coverage of energy economics and policy, and broader social issues, since the political and legislative context influence research and investment decisions.

\section{CALL FOR PAPERS}

Contributions to the journal should be submitted online at http://ema.edmgr.com

To view the Notes for Contributors please visit: www.maney.co.uk/journals/notes/ema

Upon publication in 2006, this journal will be available via the Ingenta Connect journals service. To view free sample content online visit: www.ingentaconnect.com/content/maney

For further information please contact:

Maney Publishing UK

Tel: +44 (0)113 2497481 Fax: +44 (0)1132486983 Email: subscriptions@maney.co.uk

or

Maney Publishing North America

Tel (toll free): 8662975154 Fax: 6173546875 Email: maney@maneyusa.com

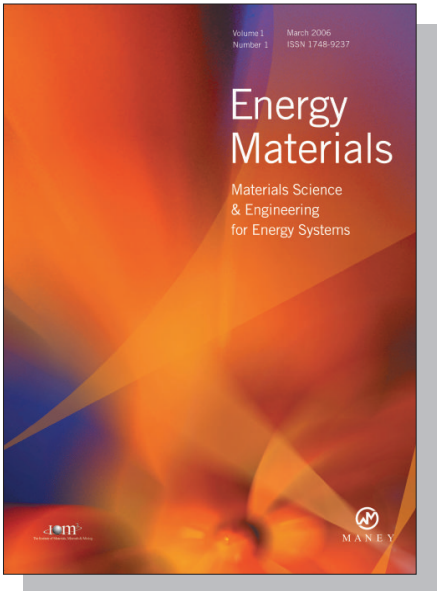

EDITORS

Dr Fujio Abe

NIMS, Japan

Dr John Hald, IPL-MPT, Technical University of Denmark, Denmark

Dr R Viswanathan, EPRI, USA

\section{SUBSCRIPTION INFORMATION}

Volume 1 (2006), 4 issues per year

Print ISSN: 1748-9237 Online ISSN: 1748-9245

Individual rate: $£ 76.00 / U S \$ 141.00$

Institutional rate: $£ 235.00 /$ US $\$ 435.00$

Online-only institutional rate: $£ 199.00 / U S \$ 367.00$

For special $\mathrm{IOM}^{3}$ member rates please email

subscriptions@maney.co.uk

\section{For further information or to subscribe online please visit www.maney.co.uk}



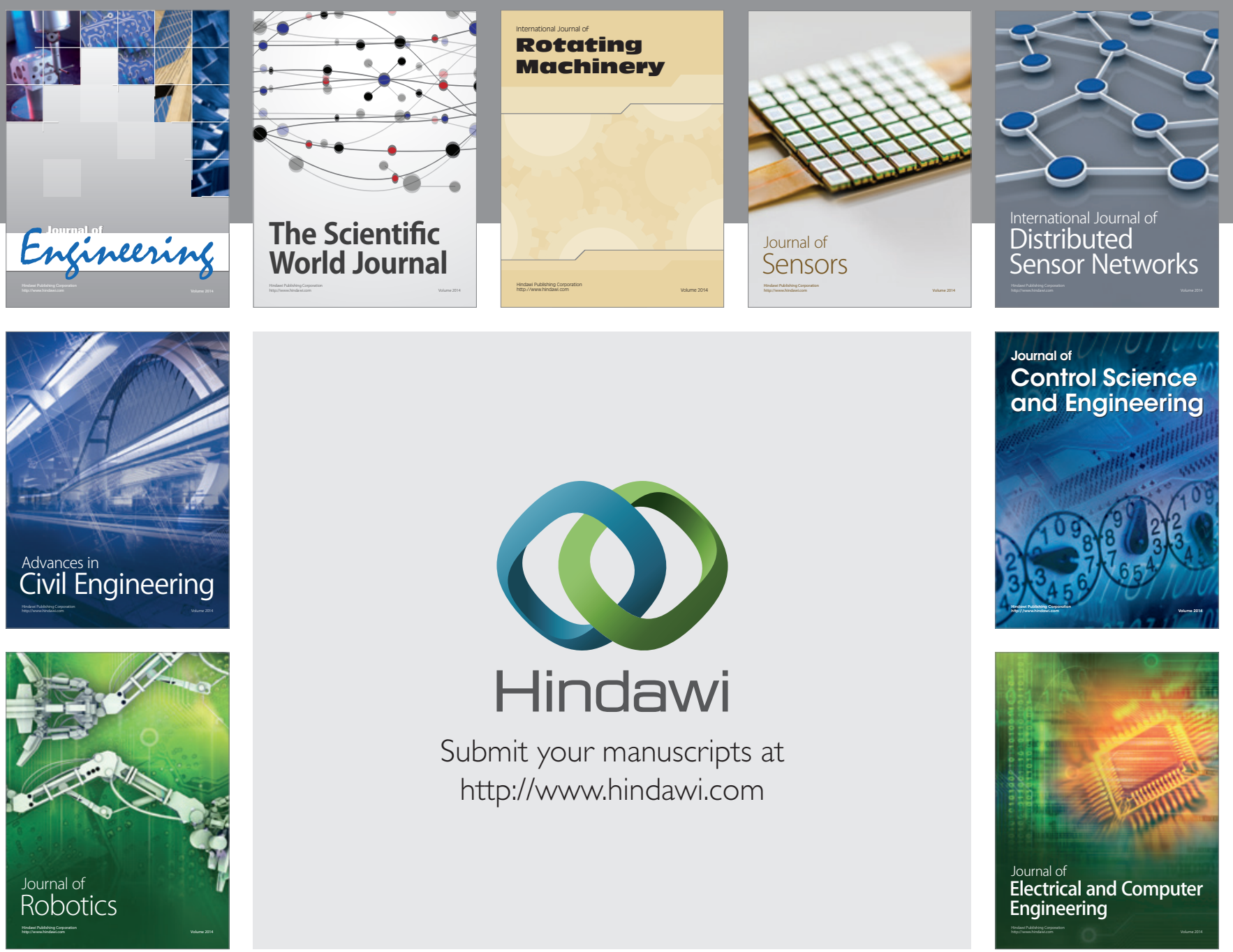

Submit your manuscripts at

http://www.hindawi.com
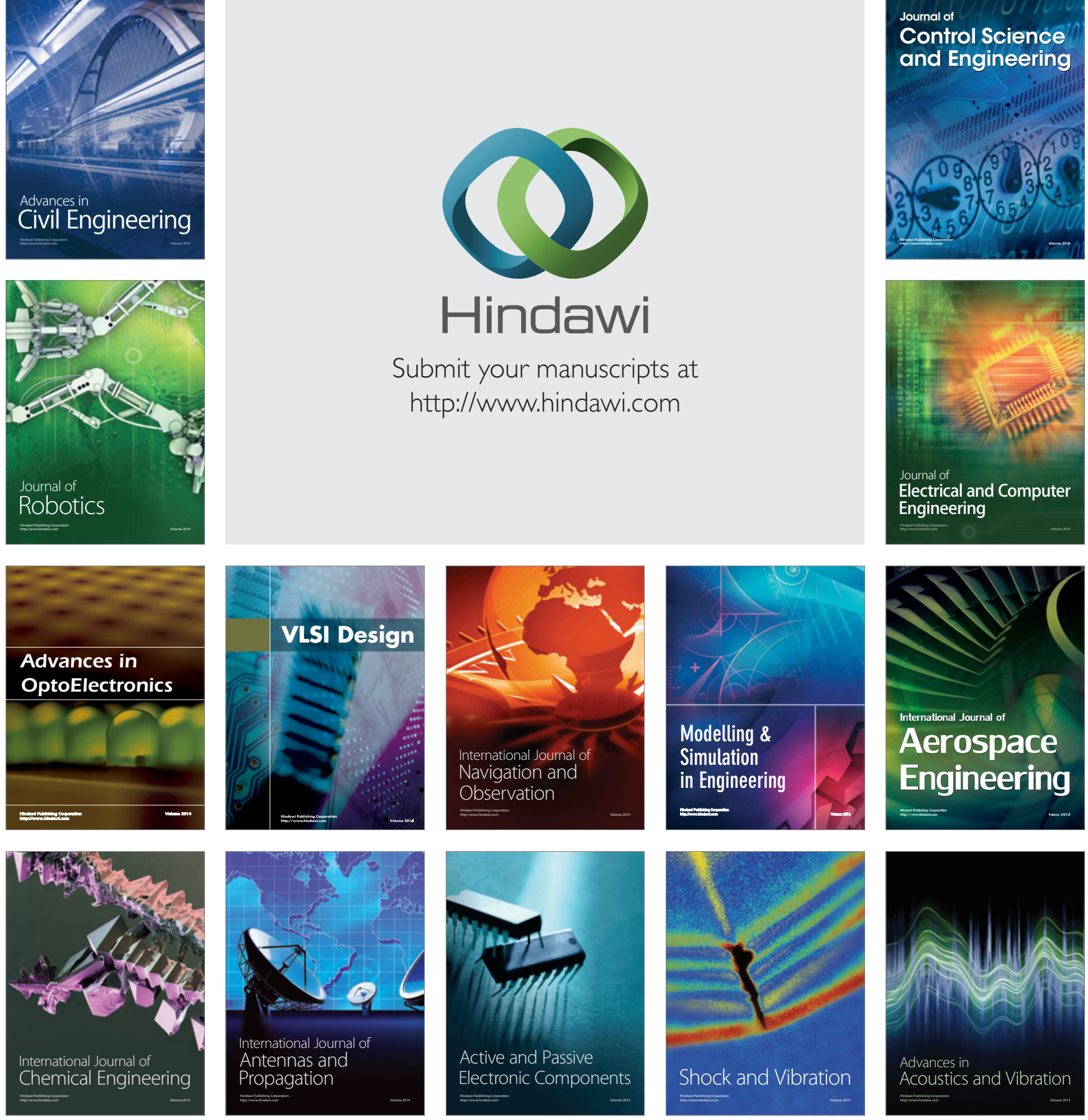